\title{
COMO IDOSOS QUE TRABALHAM CLASSIFICAM SUA QUALIDADE DE VIDA
}

\section{ARTIGO ORIGINAL}

ROCHA, Felipe Queiroz Dias ${ }^{1}$, PICCIONE, Marcelo Arruda²

ROCHA, Felipe Queiroz Dias. PICCIONE, Marcelo Arruda. Como idosos que trabalham classificam sua qualidade de vida. Revista Científica Multidisciplinar Núcleo do Conhecimento. Ano. 06, Ed. 11, Vol. 09, pp. 112-131. Novembro 2021. ISSN: 2448-0959, Link de acesso: https://www.nucleodoconhecimento.com.br/psicologia/idosos-que-trabalham, DOI: 10.32749/nucleodoconhecimento.com.br/psicologia/idosos-que-trabalham

\section{RESUMO}

A velhice resulta em transformações no idoso em função de: crise existencial, desajuste a novas funções, reforma e diminuição dos contatos sociais. A maioria dos idosos que continua a trabalhar pertence a classes sociais desfavorecidas, mas existem idosos que demonstram insatisfação em estar aposentados e intentam retornar ao ofício para se sentirem lépidos. Tendo em vista este cenário, o presente artigo é norteado pela grande valorização da qualidade de vida na terceira idade. Objetivou-se examinar como idosos que trabalham classificam sua qualidade de vida. Participaram da pesquisa 36 seniores que ainda trabalhassem, com idade média 71,5 e $\pm 5,4$. Os dados foram coletados de modo acidental na cidade de São Paulo. Para isso, foram utilizados 36 questionários WHOQOL iguais e TCLEs. Para saber se existe diferença estatisticamente significante o teste não-paramétrico do

\footnotetext{
${ }^{1}$ Mestre em Ciências da Educação pela Faculdade de Psicologia e de Ciências da Educação da Universidade do Porto (FPCEUP); Mestre em Educação e Formação de Adultos pela FPCEUP; Psicólogo e Bacharel em Psicologia pela Universidade São Judas Tadeu (USJT).

${ }^{2}$ Especialista em Psicologia do Esporte e da Atividade Física pelo Instituto Sedes Sapientiae. Psicólogo e Bacharel em Psicologia pela Universidade São Judas Tadeu (USJT).
}

RC: 101603

Link de acesso: https://www.nucleodoconhecimento.com.br/psicologia/idosos-quetrabalham 
Qui-quadrado foi aplicado. Como resultados: $80,55 \%$ dizem Concordar Totalmente com a premissa de que Deus se preocupa com os seus problemas; $63,88 \%$ Concordam Totalmente que têm uma relação significativa com Deus; $50 \%$ estão Satisfeitos com o sono e $38,88 \%$ classificam como Nada a sua necessidade de tratamento médico diário. Percebe-se que os idosos trabalhadores estão majoritariamente satisfeitos com a qualidade dos aspectos observados de suas vidas.

Palavras-chave: velhice, reforma, aposentados, terceira idade, seniores.

\section{INTRODUÇÃO}

De acordo com a Organização Mundial de Saúde (OMS), qualidade de vida é uma medida que se assenta em três eixos distintos e concomitantemente precípuos: o fato de ser pluridimensional, subjetivo e abrangente de pormenores negativos e positivos. Este objeto temático pode ser definido como a perspectiva de um indivíduo sobre a sua posição na cultura do meio social em que vive, frente às suas metas, objetivos, preocupações e padrões (TRENTINI; XAVIER e FLECK, 2006).

Na verdade, qualidade de vida detém várias conceituações nas diversas áreas do saber. Por exemplo, no campo da Economia está conexa com índices, como a renda per capita, que mostram o acesso de populações aos serviços básicos (educação, saúde e habitação). No campo da Política e da Sociologia a atenção é dirigida precisamente a uma categoria. Na Psicologia Social o maior parâmetro desse conceito é o grau de satisfação da experiência particular de um indivíduo. Por isso houve uma grande valorização da qualidade de vida na terceira idade nos últimos anos (TRENTINI; XAVIER e FLECK, 2006), a qual norteará nosso foco nesta pesquisa com um grupo de remanescentes no trabalho.

O processo de envelhecimento pode ser classificado de três formas, de acordo com o seu desenvolvimento: a primeira delas é chamada de velhice com patologia e é denotada pela presença de uma doença ou deficiência crônica que restringe 
severamente as atividades comuns do indivíduo, de modo que as suas funções outrora desempenhadas se desvigoram acentuadamente (TRENTINI; XAVIER e FLECK, 2006).

$\mathrm{Na}$ segunda, velhice usual ou normal, é plenamente comum o surgimento de patologias físicas ou psíquicas em um teor leve ou moderado, as quais causam somente modificações sutis no cotidiano dos sujeitos (TRENTINI; XAVIER e FLECK, 2006).

Por fim, a terceira classe de envelhecimento é conhecida como velhice bemsucedida ou ótima e caracteriza-se pela manutenção da saúde tal qual no período jovial, de modo a refletir no bem-estar do sujeito (TRENTINI; XAVIER e FLECK, 2006).

O envelhecimento implica consequentemente no surgimento de modificações biopsicossociais inerentes e graduais que variam em sua extemporaneidade e proporção, conforme a biogenética e, principalmente, o estilo de vida de cada sujeito. Algumas práticas que podem paliar os impactos do decurso do tempo são: manter uma dieta balanceada, fazer atividades físicas, expor-se com cuidado à radiação solar e incitar-se mentalmente. Assim, compreende-se que a velhice é um estágio em que organismo fica mais propenso a desenvolver patologias, o que é diferente de ser uma doença (ZIMERMAN, 2000).

Ou seja, o envelhecimento não é uma patologia, mas um processo de desenvolvimento humano ímpar em cada sujeito. É ainda importante considerar que as doenças decorrentes dessa fase são possíveis de sofrer intervenção nos três níveis (prevenção, diagnóstico e tratamento). Ademais, os seniores podem ter qualidade de vida mesmo que o seu corpo esteja desvigorado e exaurido (MARTINS et al., 2007).

Segundo pesquisas, os idosos precisam constantemente de apoio no trato com a saúde e comumente são auxiliados por familiares (ABREU e MATA, 2001). 
É válido mencionar que as práticas de cura são mais privilegiadas pelo sistema do que as educacionais. Deste modo, realizar ações que objetivem a educação concernente ao trato da saúde dos seniores acaba por ser um trabalho desafiador (MARTINS et al., 2007).

É relevante destacar que: em relação à satisfação com a saúde, $45 \%$ dos seniores denominaram-se satisfeitos, enquanto $40 \%$ reportaram estar satisfeitos com a sua capacidade para o trabalho (COLALTO, 2002).

Aliás, um dos aspectos que pode levar à aposentadoria adiantada é o estado de saúde. Presumivelmente os idosos que adiam a descontinuação estão bem nesse quesito (BEE, 1997).

Além disso, alguns homens e mulheres que têm filhos bem tarde, ou formaram uma nova família através de outro casamento, ou os que tutelam os netos, deverão supostamente continuar a trabalhar até que essas pessoas ligadas a eles deixem o seu $\operatorname{lar}(B E E, 1997)$.

A maioria dos idosos que continua a trabalhar pertence a classes sociais desfavorecidas e o fazem para ajudar no mantimento da sua posteridade, os quais muitas vezes voltam à família de origem por conta de relacionamentos malsucedidos (COUTRIM, 2005).

Outro quesito que pode corroborar para que os idosos evitem a aposentadoria é a não obtenção de uma condição econômica sólida durante o tempo de atividade laboral e a falta de suporte financeiro vindo dos filhos (BREVIGLIERI, 2002).

Vale destacar que apenas $5 \%$ dos idosos reportam estar completamente satisfeitos por terem dinheiro bastante para suprir as suas necessidades (COLALTO, 2002).

Numa sociedade onde as pessoas são qualificadas segundo o seu desempenho, pedir se torna um ato que conota incapacidade. Aliás, pedir nunca fez parte da identidade do idoso, até porque os sujeitos desde jovens são incentivados a não 
serem dependentes e nunca se fala da relatividade e da pluralidade embutidas no conceito de independência (ZIMERMAN, 2000).

Todavia, o idoso abstém-se de pedir qualquer tipo de ajuda porque sente que não o pode fazer, não quer ser inoportuno, pensa que a ocupação dos seus descendentes é mais significativa do que as suas necessidades e aspirações, receia ser rotulado de impertinente e ter seu status de sujeito produtivo e independente desconstruído (ZIMERMAN, 2000).

Por outro lado, existem idosos que demonstram insatisfação em estar aposentados. Há seniores que intentam retornar ao ofício para se sentirem lépidos e alentar seu ânimo e autoimagem (BREVIGLIERI, 2002).

$\mathrm{Na}$ verdade, os idosos devem planejar ações que os permitam ter satisfação neste estágio, e isto requer obter novas praxes, envolver-se em atividades proveitosas, concretizar seus planos e desejos pessoais, estudar numa universidade sênior, fazer trabalhos voluntários ou outras práticas. Em outras palavras, a velhice bem-sucedida depende de como o sênior lida com os infortúnios que the sucederem, pleiteia pelos seus direitos e executa ações plausíveis mediante a sua realidade (MARTINS et al., 2007).

Aliás, a felicidade é um indicador da qualidade de vida, o qual pode estar associado à assiduidade em cerimônias religiosas e com preferências doutrinárias. A religião influencia consideravelmente a perspectiva que o indivíduo constitui do mundo, justifica o sentido da vida e, assim, proporciona satisfação (PANZINI et al., 2007).

A religião é uma vivência que precisa converter o sujeito, uma adversidade que precisa transformar e tocar no indivíduo, e não se limitar a ser um sistema composto de dogmas, crenças e normas, mas de uma fé pessoal, que tipifica o conhecimento particular da divindade. O encontro desse espaço sacro é algo subjetivo (DINIZ, 2003).

RC: 101603

Link de acesso: https://www.nucleodoconhecimento.com.br/psicologia/idosos-quetrabalham 
Assim, alguns elementos, como os ritos (atos) e os mitos (falas), embasam todo credo e são, portanto, os ratificadores dos símbolos criados para a manifestação do deífico. Deste modo, a religião pode ser definida como a assunção das realidades transcendentais que a consciência não consegue compreender e, quando levada ao total usufruto psicológico, produz a unicidade do interior e a plenitude humana (BAPTISTA, 2003).

Inclusive, não há distinção entre os diversos estilos de vida mantidos pelos seniores nas rezas. A maioria faz preces em prol de: saúde, recebimento de paz, por amor, questões familiares e para agradecer (ORLANDO et al., 2008).

Nota-se que a vida espiritual tem altíssimo valimento na velhice, de modo que todo um grupo pesquisado disse estar em conformidade com algum credo. O motivo para tanto é a chance que uma crença Ihes traz de estabelecer uma ligação entre as suas impossibilidades e a utilização de suas capacidades; ou, quando isso não ocorre, ajuda-o a lidar com mais facilidade com a finitude deste último estágio da vida (ARAÚJO, 1999).

Deste modo, a velhice é um estágio que resulta em modificações no status do sujeito, assim como no relacionamento dele com o outro em função de: crise existencial; alteração de posição nos núcleos familiar, social e laboral; reforma; perdas variadas; diminuição dos contatos sociais devido às suas restrições (ZIMERMAN, 2000).

Essas modificações também comprometem o sono. No decurso do processo de envelhecimento usual, ocorrem alterações na quantidade e na qualidade do descanso que afetam mais da metade dos indivíduos com idade acima de 65 anos que vivem em casa e $70 \%$ dos institucionalizados, de modo a causar impactos negativos à sua qualidade de vida (GEIB et al., 2003).

As mudanças provocam alterações no sistema homeostático e repercutem sobre: aspectos psicológicos, sistema imunológico, comportamento respondente, desempenho diário geral, capacidade de adaptação e estado de humor. As causas

RC: 101603

Link de acesso: https://www.nucleodoconhecimento.com.br/psicologia/idosos-quetrabalham 
que geralmente ocasionam esse tipo de distúrbio na velhice são: dores, fatores ambientais, desconfortos emocionais e alterações no padrão de sono, como maior latência, dificuldade de reiniciá-lo e duração reduzida (GEIB et al., 2003).

Além dessas queixas, a sonolência e a fadiga diurna são comuns, bem como o aumento de cochilos, o comprometimento cognitivo e do desempenho cotidiano e diversos outros problemas, que, embora não sejam específicos do envelhecimento, têm grande impacto sobre os idosos. A falta de adaptação às perturbações emocionais, os hábitos inadequados, alguns transtornos orgânicos e afetivos, o uso de substâncias (psicotrópicas ou outras), a agitação noturna e as quedas são possíveis consequências. Esses sintomas permitem afirmar que sono e o repouso são funções restauradoras fulcrais para a manutenção da vida (GEIB et al., 2003).

Entre os fatores psicossociais, responsáveis pelos distúrbios de sono no idoso, estão o luto, a aposentadoria e as modificações no ambiente social, tais como isolamento, institucionalização e dificuldades financeiras. A morte do cônjuge tem um forte impacto na velhice, podendo estar associada ou não à depressão. A aposentadoria e as modificações no ambiente social, quando rompem com os hábitos normais do idoso, contribuem para reduzir a amplitude do ritmo sono-vigília, produzindo fragmentação do sono noturno e cochilos durante o dia, usados como fuga à monotonia (GEIB et al., 2003).

Outro fator significativo na dificuldade dos idosos para dormir é a intensidade de uma dor crônica (ALVES et al., 2019).

Porém, além das alterações no corpo, o envelhecimento traz ao ser humano uma série de transformações psicológicas que podem resultar em desajuste a novas funções, desmotivação, dificuldade para organizar o futuro, carência de suporte para lidar com as perdas orgânicas, emocionais e sociais, dificuldade de se adequar às mudanças rápidas, modificações psíquicas que exigem apoio profissional e defasagem da autoestima e imagem de si (NERI, 2001). 
Segundo estudos internacionais, $15 \%$ dos idosos precisam de apoio psicológico e $2 \%$ têm depressão. Frequentemente, estas demandas não são identificadas pela família e pelos cuidadores, ao invés disso são taxadas como peculiaridades do estágio da velhice (ZIMERMAN, 2000).

Aliás, somente $40 \%$ dos idosos reportam estar satisfeitos com o serviço de saúde que possuem (COLALTO, 2002), apesar de serem concordantes ao dizer que não estão satisfeitos com tal assistência médica devido à impossibilidade de falar de suas queixas e não Ihes serem feitas perguntas. Às vezes, os profissionais nem thes olham diretamente (BERES, 1994).

A conversação do sênior com o profissional de saúde gera trocas interpessoais, as quais, em conjunto do conhecimento já popularmente disseminado, ajudam a suplantar falhas presentes no exercício educacional de saúde tradicional. Assim sendo, há possibilidade para os idosos requererem seus interesses autonomamente enquanto sujeitos sociais capazes de tanto (MARTINS et al., 2007).

Teve-se por objetivo geral examinar como os idosos trabalhadores classificam a sua própria qualidade de vida.

Os objetivos específicos são:

- Analisar o andamento de alguns aspectos da vida dos idosos que continuam a trabalhar;

- Ouvir dos idosos que ainda trabalham como estão alguns aspectos de suas vidas;

- Verificar com criticidade o estado de alguns aspectos de suas vidas.

RC: 101603

Link de acesso: https://www.nucleodoconhecimento.com.br/psicologia/idosos-quetrabalham 


\section{METODOLOGIA}

\section{PARTICIPANTES}

Esta pesquisa teve 36 idosos (88,90\% homens e 11,10\% mulheres) como participantes, os quais tinham idade igual ou superior a 65 anos (que é a faixa etária definida pela OMS para a reforma) e que estivessem trabalhando com ou sem vínculo empregatício, constante ou inconstantemente. Verificou-se que a amplitude de idade é de 22 anos (a menor idade é 65 e a maior é 87), a idade média é 71,5 anos, o desvio padrão é de 5,4 e a mediana é 71 anos.

\section{MATERIAL}

O material utilizado foi o questionário WHOQOL; foram 36 unidades iguais entre si para recolher os dados. Este instrumento foi escolhido devido ao seu reconhecimento internacional para examinar a qualidade de vida em seus vários aspectos.

O instrumento tratava-se de um questionário dividido em três etapas: a primeira para caracterizar o participante; a segunda parte consistia em uma série de perguntas fechadas sobre diversos aspectos que compõem a compreensão geral do que é qualidade de vida no escopo da Psicologia Social; a última parte continha sentenças afirmativas e negativas que possibilitavam ao participante expor sua percepção a elas relativamente ao seu contexto - isto é, havia uma série de frases em que o participante reportava em que grau concordava ou discordava delas no que tange a sua vida.

\section{PROCEDIMENTOS}

Procedeu-se de modo fortuito na recolha dos dados: os sujeitos foram procurados e encontrados acidentalmente nos meses de janeiro e fevereiro e caso estivessem nas 
condições estabelecidas pelo objetivo (trabalhando e que tinham 65 anos de idade ou mais) eram admitidos pelos pesquisadores.

No primeiro momento nos apresentávamos e explicávamos o propósito da nossa pesquisa. Posteriormente, se o indivíduo estivesse em conformidade com os nossos objetivos de investigação e aceitasse participar voluntariamente, Ihe introduzíamos o Termo de Consentimento Livre e Esclarecido (TCLE) e o questionário WHOQOL, assim como the prestávamos qualquer tipo de esclarecimento sobre estes documentos e os seus itens, os quais continham os nossos contatos. É importante destacar que o presente trabalho é parte de um projeto maior, o qual foi aprovado no Comitê de Ética e Pesquisa no 017/2005 e na CAAE 005.0.237.000.05.

Todos os participantes foram abordados na cidade de São Paulo, sendo a grande maioria encontrada em bairros próximos um do outro: 15 na Mooca, seis no Brás, outros seis na Sé, cinco na Zona Cerealista, três na Vila Mariana e um no Cambuci.

\section{RESULTADOS E DISCUSSÃO}

Alguns resultados obtidos nos questionários WHOQOL utilizados serão apresentados e discutidos estatística e criticamente nas tabelas a seguir.

Tabela 1 - Ocupação

\begin{tabular}{|c|c|c|}
\hline Áreas & $\mathrm{F}$ & $\%$ \\
\hline Área das ciências e artes & 10 & 27,77 \\
\hline $\begin{array}{l}\text { Área de vendas e } \\
\text { comércios }\end{array}$ & 15 & 41,66 \\
\hline Área de bens industriais & 8 & 22,22 \\
\hline Outras & 3 & 8,33 \\
\hline Total & 36 & 100 \\
\hline
\end{tabular}

Fonte: questionários WHOQOL

RC: 101603

Link de acesso: https://www. nucleodoconhecimento.com.br/psicologia/idosos-quetrabalham 
$\mathrm{Na}$ Tabela 1, nota-se que, dentre os participantes, $41,66 \%$ são trabalhadores da Área de vendas e comércio, 27,77\% trabalham na Área das ciências e artes, 22,22\% são da Área de bens industriais e somente 8,33\% relataram pertencer a Outra área.

Segundo o teste não-paramétrico do Qui-quadrado - que foi aplicado para verificar se existe diferença estatisticamente significante - não há diferença estatisticamente significante, dado: $x_{0}^{2}=2,35$ e $x^{2} c=7,81$, além de n.g.l. $=3$ e $\alpha=0,05$.

As variáveis da Tabela 1 foram sistematizadas de acordo com as categorias da Classificação Brasileira de Ocupações (CBO), mencionadas no site do Ministério do Trabalho e Emprego: http://www.mtecbo.gov.br. As ocupações da CBO que não se encontravam dentre as praticadas pelos idosos foram descartadas da tabela.

O material utilizado levanta a profissão de cada participante, mas não investiga o caminho que levou o sujeito à escolha dessa área de atuação, o seu percurso ou as circunstâncias que o levaram a exercer o ofício atual, de modo ser totalmente impreciso propor qualquer hipótese que pormenorize o seu ramo de atividade com base em qualquer outro dado obtido na coleta de dados e na literatura consultada. $O$ que se pode fazer é discutir hipóteses das possíveis razões pelas quais os voluntários continuam à prática dessas atividades.

Coutrim (2005), por exemplo, diz que a maior parte dos idosos que continua a exercer atividades de trabalho é de classes sociais desfavorecidas, as quais requerem a sua colaboração no orçamento familiar para a subsistência de sua posteridade, pois seus filhos comumente retornam a suas casas por fracassarem em seus relacionamentos.

Em concordância, Breviglieri (2002) diz que a falta de uma estabilidade econômica durante os anos de trabalho e de suporte financeiro por parte dos filhos também corrobora para que os idosos não se aposentem, de modo a demonstrarem necessidade de retorno às atividades remuneradas. Bee (1997) enriquece estas palavras ao dizer que a paternidade ou maternidade tardia, assim como a constituição de outra família, podem demandar que o sujeito permaneça no trabalho

RC: 101603

Link de acesso: https://www.nucleodoconhecimento.com.br/psicologia/idosos-quetrabalham 
até que os seus dependentes tenham condições o suficiente para se manterem, o que deve procrastinar a sua aposentadoria por consequência.

É válido ressaltar que Colalto (2002) diz que somente $5 \%$ dos idosos dizem estar completamente satisfeitos por terem dinheiro suficiente para satisfazer suas necessidades e $40 \%$ dos idosos estão satisfeitos com a sua capacidade para o trabalho.

Aliás, Bee (1997) também diz que um dos fatores que pode adiantar a aposentadoria é o estado de saúde. Presumivelmente os idosos que param tardiamente estão bem nesse quesito.

Deste modo, observa-se que a necessidade econômica é uma das grandes razões que leva à permanência de seniores no mercado de trabalho, a qual, por outro lado, tende a depender do estado de saúde do sujeito, uma vez que este aspecto pode levar à aposentadoria precoce. Assim, o idoso pode estar em um paradoxo: ao mesmo tempo em que precisa trabalhar não o pode ou não consegue devido às suas condições físicas.

Ademais, Zimerman (2000) diz que pedir é um ato que não faz parte da identidade do idoso e nem um constructo social bem-visto, uma vez que a sociedade avalia os cidadãos pelo que são capazes de produzir. O sênior evita requerer qualquer tipo de suporte por: sentir que não tem este direito, não querer causar incômodos, acreditar que a ocupação dos filhos e netos é mais importante do que as suas necessidades e desejos, temer ser considerado inconveniente e finalmente ser ou sentir-se destituído de seu status de sujeito produtivo e independente. Sobre esta última causa, Breviglieri (2002) diz haver certa dificuldade dos idosos em continuarem aposentados; os seniores manifestam vontade de retornar ao trabalho por desejarem se sentir lépidos e alentar o seu ânimo e autoimagem.

O trabalho é uma faceta que compõe a autoimagem do idoso, a ruptura com o ofício tende a ferir a sua perspectiva de si mesmo e como consequência altera a forma como o sujeito lida com familiares e outras pessoas, pois muitas vezes o sênior RC: 101603

Link de acesso: https://www.nucleodoconhecimento.com.br/psicologia/idosos-quetrabalham 
trabalhou e participou da criação destes indivíduos que hoje o têm que sustentar e auxiliar, o que não é aceito com facilidade. De acordo com Zimerman (2000), este efeito da velhice modifica o status do idoso devido a: crise existencial, alteração de papéis concernentes ao trabalho e à sociedade, aposentadoria, perdas variadas, situação financeira e outras razões.

Tabela 2 - Necessidade de tratamento médico para a vida diária

\begin{tabular}{|l|l|l|}
\hline Necessidade & F & $\%$ \\
\hline Nada & 14 & 38,88 \\
\hline Muito pouco & 6 & 16,66 \\
\hline $\begin{array}{l}\text { Mais ou } \\
\text { menos }\end{array}$ & 8 & 22,22 \\
\hline $\begin{array}{l}\text { Bastante } \\
\text { Extremamente }\end{array}$ & 7 & 19,44 \\
\hline Total & $\mathbf{3 6}$ & $\mathbf{1 0 0}$ \\
\hline
\end{tabular}

Fonte: questionários WHOQOL

Na Tabela 2, com relação à necessidade de intervenção médica, Nada foi à opção mais respondida pelos participantes com $38,88 \%$. Além disso, $22,22 \%$ dos idosos optaram pela variável Mais ou menos enquanto $19,44 \%$ e $16,66 \%$ dos sujeitos da pesquisa escolheram as variáveis Bastante e Muito pouco, respectivamente. Apenas 2,77\% se mostraram Extremamente necessitados de tratamento médico.

O teste do Qui-quadrado foi aplicado com o fim de verificar se há diferença estatisticamente significante. Resultou-se: $x_{0}^{2}=4,42$ e $x^{2}{ }_{c}=9,48$, não havendo tal diferença, considerando, ainda, n.g.l. $=4$ e $\alpha=0,05$.

Dessa forma, o tratamento médico, apesar da maioria das opiniões relacionadas a Nada e Muito pouca necessidade, se faz presente no contexto dos idosos. 
Trentini; Xavier e Fleck (2006) discorrem sobre as velhices com patologia, usual e bem-sucedida, as quais correspondem ao desenvolvimento do envelhecimento humano: a primeira acompanhada de disfunções físicas ou mentais que limitam criticamente as ações do idoso, a segunda com o surgimento dessas disfunções num teor brando que provoca somente mudanças parciais e a terceira com a conservação plena de saúde como dos jovens adultos. Com base nessa classificação, pode-se dizer que os participantes que reportaram como Nada $(38,88 \%)$ a sua necessidade de tratamento médico diariamente desfrutam de um estado bem-sucedido de velhice, enquanto os que disseram Muito pouco ou Mais ou menos (38,88\%) detêm um processo de velhice usual, ao passo que os $22,22 \%$ que categorizam sua necessidade como Bastante ou Extremamente têm uma velhice com patologia.

É possível reclassificar estes dados se considerarmos que os participantes que reportam sua necessidade de tratamento médico diário como Muito pouco tenham uma velhice bem-sucedida por sabermos que muitos jovens adultos eventualmente desenvolvem problemas de saúde que também requerem tratamento diário, de modo que pouco mais da metade $(55,54 \%)$ usufruiria de uma velhice bem-sucedida e $22,22 \%$ de uma velhice usual, o que no fim, continuaria a denotar a menor parte dos voluntários como detentores do processo de envelhecimento com patologia e uma ligeira maioria como idosos usuais ou bem-sucedidos.

Zimerman (2000) corrobora as palavras do trio ao dizer que envelhecer prognostica sofrer modificações biopsicossociais de forma natural e gradativa e em maior ou menor grau, a depender do sujeito. Os efeitos dessas modificações podem, segundo Bee (1997), determinar a continuidade no trabalho, uma vez que o íntegro estado de saúde é um fator relevante para o seu prosseguimento, o qual posterga a aposentadoria.

Martins et al. (2007) complementam ao discorrer que o envelhecimento é um fenômeno que se desdobra de modo ímpar em cada indivíduo, e não uma patologia, até pelas doenças decorrentes deste estágio serem passíveis de diagnóstico, 
tratamento e prevenção. Entretanto, de acordo com Colalto (2002), 45\% dos idosos estão satisfeitos com a própria saúde e $40 \%$ estão satisfeitos com o serviço de saúde que têm. Beres (1994) vai mais além e diz que os idosos são unânimes em reportar sua insatisfação com a assistência médica recebida devido aos profissionais não lhes concederem tempo para falar de suas queixas, não fazerem perguntas e às vezes nem os olhares diretamente.

Segundo Martins et al. (2007), a valorização das trocas interpessoais permeadas pelo diálogo entre o paciente e o médico pode ajudar a suplantar os hiatos presentes no exercício educacional de saúde tradicional se considerar a importância do conhecimento popular. Dessa forma, há possibilidade para a autonomia dos idosos na condição de sujeitos sociais capazes de requererem seus interesses. No mais, é possível que os idosos vivam bem e com qualidade mesmo que o seu corpo esteja exaurido ou desvigorado. De acordo com Zimerman (2000), a dieta balanceada, a prática de atividades físicas, a exposição cuidadosa à radiação solar e a incitação mental são algumas ações que podem paliar estes impactos do envelhecimento.

Por suas vezes, Abreu e Mata (2001) reportam que pesquisas feitas com idosos sobre a necessidade de ajuda nos cuidados com a saúde mostram que todos os sujeitos recebem auxílio de seus familiares neste âmbito. No entanto, conforme dizem Martins et al. (2007), o sistema privilegia mais as ações de cura do que as educacionais, de modo a procrastiná-las por consequência. Daí promover uma boa educação no que concerne ao trato da saúde dos seniores se torna um trabalho desafiador.

Tabela 3 - Satisfação no sono

\begin{tabular}{|l|l|l|}
\hline Prazer & F & $\%$ \\
\hline Muito satisfeito & 1 & 2,77 \\
\hline Insatisfeito & 5 & 13,88 \\
\hline $\begin{array}{l}\text { Nem satisfeito } \\
\text { insatisfeito }\end{array}$ & 8 & 22,22 \\
\hline
\end{tabular}

RC: 101603

Link de acesso: https://www.nucleodoconhecimento.com.br/psicologia/idosos-quetrabalham 


\begin{tabular}{|l|l|l|}
\hline Satisfeito & 18 & 50 \\
\hline Muito satisfeito & 3 & 8,33 \\
\hline Total & $\mathbf{3 6}$ & $\mathbf{1 0 0}$ \\
\hline
\end{tabular}

Fonte: questionários WHOQOL

Pelo que se observa na Tabela 3, metade (50\%) dos entrevistados diz estar Satisfeita com seu sono. Dessa forma, outros 22,22\% optaram pela alternativa $\mathrm{Nem}$ satisfeito nem insatisfeito. Por outro lado, $13,88 \%$ se consideram Insatisfeitos, enquanto $8,33 \%$ e 2,77\% avaliam suas escolhas como Muito satisfeito e Muito insatisfeito.

Vale salientar que $x_{0}^{2}=8,96$ e $x^{2}{ }_{c}=9,48$, sendo que $o$ teste do Qui-quadrado foi aplicado com o intuito de averiguar se há diferença estatisticamente significante; descobriu-se que tal diferença não existe. Ainda se sabe que n.g.l. $=4$ e $\alpha=0,05$.

Os participantes que estão satisfeitos em alguma medida com o sono são $58,33 \%$ (os que se classificaram como Satisfeitos e Muito satisfeitos), uma quantidade sensivelmente similar aos que reportam como Nada e Muito pouco a necessidade de tratamento médico diariamente, na Tabela 2: $55,54 \%$. Deste modo, entende-se que a boa saúde, que dispensa a necessidade constante de recursos médicos, pode estar associada à qualidade do sono (ou vice-versa). Essa equiparação também pode estar relacionada às palavras de Trentini, Xavier e Fleck (2006) no que concerne aos três tipos de velhice: os que se dizem Satisfeitos e Muito satisfeitos $(58,33 \%)$ detêm um processo bem-sucedido, os que reportam como Nem satisfeito nem insatisfeito $(22,22 \%)$ têm um envelhecimento usual e os que consideram Insatisfeitos e Muito insatisfeitos (16,65\%) passam pelo estágio com patologia. Ao considerar este prisma, pode-se perceber que mais da metade dos participantes têm um ótimo desenvolvimento, pouco menos de $1 / 4$ passam por este estágio de forma usual ou normal e $16,65 \%$ o detêm com patologias.

RC: 101603

Link de acesso: https://www.nucleodoconhecimento.com.br/psicologia/idosos-quetrabalham 
Por outro lado, os resultados da Tabela 3 são incompatíveis com os citados por Geib et al. (2003) sobre os idosos que não trabalham e são institucionalizados; os autores dizem que o processo de envelhecimento usual causa modificações na quantidade e qualidade do sono e, assim, afeta mais da metade dos indivíduos com idade acima de 65 anos que vivem em casa e 70\% dos institucionalizados, o que traz um impacto negativo à sua qualidade de vida.

Sobre isso, os mesmos autores (GEIB et al., 2003) falam que essas modificações também provocam alterações no sistema homeostático e se estendem a: aspectos psicológicos, sistema imunológico, comportamento respondente, desempenho diário geral, capacidade de adaptação e estado de humor. As causas que geralmente ocasionam esse tipo de distúrbio na velhice são: dores, fatores ambientais, desconfortos emocionais e alterações no padrão de sono (como maior latência, dificuldade de reiniciá-lo e duração reduzida), sonolência, fadiga diurna, aumento de cochilos, comprometimento cognitivo e outros sintomas que não são próprios do envelhecimento, mas têm grande impacto sobre os idosos.

Geib et al. (2003) ainda dizem que a incapacidade de adaptação às perturbações emocionais, os hábitos inadequados, alguns transtornos orgânicos e afetivos, o uso de substâncias (psicotrópicas ou outras), a agitação noturna e as quedas são exemplos de possíveis consequências. Toda essa sintomatologia permite afirmar que o sono e o repouso são funções restauradoras necessárias para a manutenção da vida.

Entre os fatores psicossociais, responsáveis pelos distúrbios de sono no idoso, estão o luto, a aposentadoria e as modificações no ambiente social, tais como isolamento, institucionalização e dificuldades financeiras. A morte do cônjuge tem um forte impacto na velhice e pode estar associada à depressão, enquanto a aposentadoria e as modificações no ambiente social, quando rompem com os hábitos comuns do idoso, contribuem para reduzir a amplitude do ritmo sono-vigília, o que produz a fragmentação do sono noturno e cochilos durante o dia, usados como fuga à monotonia (GEIB et al., 2003). 
Pela perspectiva biológica, Alves et al. (2019) dizem que a dor crônica é um fator que interfere relevantemente no sono dos idosos.

Tabela 4 - Falta de certeza sobre o significado da existência humana

\begin{tabular}{|l|l|l|}
\hline Incerteza & F & $\%$ \\
\hline $\begin{array}{l}\text { Concordo Totalmente } \\
\text { Concordo Parcialmente }\end{array}$ & 5 & 13,88 \\
\hline $\begin{array}{l}\text { Concordo mais que } \\
\text { discordo }\end{array}$ & 4 & 13,88 \\
\hline $\begin{array}{l}\text { Discordo mais que } \\
\text { concordo }\end{array}$ & 6 & 16,66 \\
\hline $\begin{array}{l}\text { Discordo Parcialmente } \\
\text { Discordo Totalmente }\end{array}$ & 8 & 22,22 \\
\hline Total & 8 & 22,22 \\
\hline
\end{tabular}

Fonte: questionários WHOQOL

Os resultados da Tabela 4 mostram que há equilíbrio entre as opiniões sobre o significado da existência humana. A maior parte dos entrevistados, $22,22 \%$, aparece tanto como a porcentagem final dos que optaram pela alternativa Discordo Parcialmente quanto da alternativa Discordo Totalmente. Além disso, 16,66\% optaram por Discordo mais que concordo, 13,88\% dizem: Concordo Parcialmente, outros 13,88\% Concordo Totalmente e 11,11\% Concordo mais que discordo.

Com o intuito de averiguar se existe diferença estatisticamente significante, foi aplicado o teste não-paramétrico do Qui-quadrado, que resultou: $x_{0}^{2}=3,44$ e $x^{2}=11,07$, não havendo, portanto, diferença estatisticamente significante. Considerase ainda n.g.l. $=5$ e $\alpha=0,05$.

Panzini et al. (2007) dizem que a religião influencia na perspectiva que o indivíduo tem do mundo, pode explicar o sentido da vida e trazer satisfação. Neste sentido, percebe-se na Tabela 5 que 94,43\% dos idosos trabalhadores concordam em algum

RC: 101603

Link de acesso: https://www.nucleodoconhecimento.com.br/psicologia/idosos-quetrabalham 
grau com a premissa de terem uma relação pessoal significativa com Deus, enquanto na Tabela 6 vê-se que $97,21 \%$ concordam em alguma medida que Deus se preocupa com os seus problemas.

Baptista (2003) define a religião como a compreensão das realidades transcendentais não compreendidas pela consciência as quais levam à unicidade interior em seu ápice.

Observa-se que o impacto de uma crença religiosa para os idosos é altíssimo, contudo, este aspecto parece não determinar plenamente a perspectiva que os sujeitos têm acerca do significado da existência humana, dado o nivelamento de respostas apresentados na Tabela 4. Ou seja, há possibilidade desta variável influenciar sua visão de mundo, e não garantia.

Tabela 5 - Significância da relação pessoal com Deus

\begin{tabular}{|c|c|c|}
\hline Significância & $\mathrm{F}$ & $\%$ \\
\hline Concordo Totalmente & 23 & 63,88 \\
\hline Concordo Parcialmente & 7 & 19,44 \\
\hline $\begin{array}{l}\text { Concordo mais que } \\
\text { discordo }\end{array}$ & 4 & 11,11 \\
\hline $\begin{array}{l}\text { Discordo mais que } \\
\text { concordo }\end{array}$ & 1 & 2,77 \\
\hline Discordo Totalmente & 1 & 2,77 \\
\hline Total & 36 & 100 \\
\hline
\end{tabular}

Fonte: questionários WHOQOL

Observa-se, na Tabela 5, que entre os idosos participantes da pesquisa, 63,88\% Concordam Totalmente que têm uma relação significativa com Deus, entre os outros entrevistados, 19,44\% Concordam Parcialmente, 11,11\% disseram Concordar mais que discordar, $2,77 \%$ dos idosos Discordam mais que concordam e outros $2,77 \%$ 
Discordam totalmente. A alternativa Discordo Parcialmente não foi escolhida por nenhum participante e por isso foi retirada da tabela.

Para averiguar se existe diferença estatisticamente significante aplicou-se o teste não-paramétrico do Qui-quadrado. Obteve-se $x_{0}{ }^{2}=8,53$ e $x^{2}{ }_{c}=9,48$, não existindo diferença estatisticamente significante. Também se considera n.g.l. $=4$ e $\alpha=0,05$.

Orlando et al. (2008) dizem que a maior parte dos idosos reza por objetivos como saúde, paz, amor, resolução de questões familiares e agradecer por favores alcançados, o que configura um tipo de relação com Deus através dessas petições.

Diniz (2003) diz que o encontro pessoal com Deus por meio da fé, além dos dogmas e normas pré-estabelecidas pelo sistema de crenças, toca e transforma o indivíduo, e é esse ponto que caracteriza a religião. Baptista (2003), por sua vez, entende religião como a assunção das realidades transcendentais que a consciência não compreende e quando levada ao total usufruto psicológico produz a totalidade do ser humano em seu interior, embora considere que os ritos e mitos fundamentem a construção de todas as religiões e são eles, portanto, os validadores dos símbolos criados para a expressão do sagrado em nós.

Araújo (1999) continua a dizer que este aspecto tem grande influência na velhice, de modo que $100 \%$ da população que pesquisou disse estar em conformidade com algum credo. Essa aderência decorre porque a prática de uma religião pelo idoso permite-lhe estabelecer uma conexão entre suas impossibilidades e a utilização de suas capacidades ou, quando isso não ocorre, ajuda-o a lidar com mais facilidade com essa etapa final da vida.

Panzini et al. (2007) completa ao dizer que as doutrinas e a assiduidade em cerimônias religiosas promovem a felicidade, instigam a visão de mundo e explicam o sentido da vida.

No mais, a Tabela 5 mostra que $94,43 \%$ dos participantes dizem que concordam de algum modo com a premissa de terem uma relação pessoal significativa com Deus, 
semelhante à Tabela 6 , na qual se percebe que $97,21 \%$ concordam de alguma forma que Deus se preocupa com os seus problemas. Além do alto índice de espiritualidade verificado nesses dois resultados, é possível correlacioná-los entre si e compreender que a relação pessoal com Deus pode se dar devido à preocupação do Ser Divino com os problemas dos devotos, de modo a configurar um contexto favorável à relação interpessoal num enquadramento espiritual e a construção de símbolos e dogmas advindos dessa mesma relação.

Tabela 6 - Preocupação de Deus com os problemas

\begin{tabular}{|l|l|l|}
\hline Variáveis & F & $\%$ \\
\hline Concordo Totalmente & 29 & 80,55 \\
\hline $\begin{array}{l}\text { Concordo Parcialmente } \\
\text { Concordo mais que } \\
\text { discordo }\end{array}$ & 4 & 11,11 \\
\hline $\begin{array}{l}\text { Discordo Parcialmente } \\
\text { Total }\end{array}$ & 1 & 5,55 \\
\hline & $\mathbf{3 6}$ & $\mathbf{1 0 0}$ \\
\hline
\end{tabular}

Fonte: questionários WHOQOL

Observando a Tabela 6, nota-se que $80,55 \%$ dos participantes Concordam Totalmente com a afirmação de que Deus se preocupa com os seus problemas. Apenas 11,11\% Concordam Parcialmente e 5,55\% Concordam mais que discordam. Somente 2,77\% Discordam Parcialmente. As alternativas Discordo Totalmente e Discordo mais que concordo foram eliminadas por não terem sido citadas por nenhum sujeito.

Vale ressaltar que $x_{0}^{2}=0$ e $x^{2} c=7,81$; uma vez que 0 teste do Qui-quadrado foi aplicado com a intenção de descobrir se existe diferença estatisticamente significante; descobriu-se que não existe tal diferença. Frisa-se também que n.g.I.=3 e $\alpha=0,05$. 
De acordo com Orlando et al. (2008), maioria dos idosos ora por propósitos como saúde, paz, amor, solução de problemas familiares e agradecimento por favores obtidos. A prática dessas orações denota a crença deles com a preocupação divina por seus problemas, pois por meio da prece suas queixas são apresentadas para serem solucionadas neste espaço sagrado, nas palavras de Diniz (2003).

O mesmo Diniz (2003) define religião como uma experiência transformadora sobre o indivíduo, não um sistema concreto composto por moral, doutrinas e credo, mas uma fé que produz o encontro pessoal com Deus. A experiência desse espaço sagrado é estritamente subjetiva. Panzini et al. (2007) corrobora ao declarar que a felicidade está associada à participação em serviços religiosos e a preferências doutrinárias, as quais influenciam de forma significativa a visão que o indivíduo tem do mundo.

Baptista (2003), por sua vez, conceitua religião como a assunção das realidades transcendentais que a consciência não consegue compreender e que levada ao pleno usufruto psicológico ocasiona a unicidade e a totalidade interior do ser humano.

Segundo Araújo (1999), o aspecto espiritual influencia bastante nessa etapa da vida, de forma que $100 \%$ de seus participantes disseram estar em conformidade com alguma atividade religiosa. Quanto às razões para a ocorrência desse fato, verificase que a prática de uma religião pelo idoso permite-lhe estabelecer um elo entre as suas impossibilidades e a utilização de suas capacidades ou, quando isso não ocorre, ajuda-o a lidar com essa última fase da vida.

Ademais, na Tabela 6 se observa que 97,21\% dos participantes concordam em algum grau que Deus se preocupa com os seus problemas, uma porcentagem similar à da Tabela 5 , a qual diz que $94,43 \%$ concordam em alguma proporção com a premissa de terem uma relação pessoal significativa com Deus. A altíssima taxa de espiritualidade é evidente nessas duas tabelas, as quais se correspondem 
quando entendemos que a preocupação divina com os problemas dos seniores fomenta a relação pessoal deles com Deus.

A faceta espiritual, assim, se mostra como a mais preponderante na vida dos idosos trabalhadores.

\section{CONSIDERAÇÕES FINAIS}

Em resposta a questão norteadora, percebeu-se que os idosos que trabalham estão majoritariamente satisfeitos com a qualidade dos aspectos observados de suas vidas. Em especial, pôde-se notar uma grandíssima aderência à religiosidade, de modo a ser esta uma faceta quase absoluta na perspectiva dos participantes, o que está em consonância com as palavras de Araújo (1999) acerca do suporte que esta área proporciona no enfrentamento desta etapa final da vida. Estudos mais específicos e aprofundados sobre a vida religiosa dessa categoria podem ser feitos para se levantar informações mais pormenorizadas.

Os demais aspectos observados também detiveram uma maioria de respostas reconhecidas como de satisfação, embora com maior distribuição entre todos os níveis, de acordo com as variáveis das tabelas. Compreende-se que esta preeminência decorra do processo de velhice bem-sucedida, nas palavras de Trentini; Xavier e Fleck (2006), o qual também possibilita a permanência dos idosos nas atividades laborais (BEE, 1997).

Além disso, as mudanças peculiares do processo de envelhecimento citados por Neri (2001) não foram observadas no grupo amostral: dificuldades de adaptação a novas funções; desmotivação; necessidade de trabalhar as perdas; dificuldade de se adaptar às mudanças rápidas; modificações psíquicas que requerem apoio profissional; defasagem da autoimagem e autoestima. Provavelmente pelas mesmas razões supracitadas.

Como anteriormente dito, este trabalho teve por objetivo investigar a qualidade de algumas áreas da vida dos idosos que trabalham por uso de um questionário

RC: 101603

Link de acesso: https://www.nucleodoconhecimento.com.br/psicologia/idosos-quetrabalham 
padronizado. Este material quantificou as respostas dos participantes e possibilitou a criação de hipóteses fundamentadas na literatura consultada, entretanto percebe-se a existência de lacunas entre estas mesmas respostas e as suas causas, o que inviabiliza uma análise crítica de maior rigor. Conforme já sugerido, outros estudos mais detalhados podem ser realizados para se investigar qualitativamente estas e outras áreas destes sujeitos, da mesma forma que uma replicação deste trabalho com seniores que não trabalham para entremear os resultados de ambas as categorias: aposentados e trabalhadores.

No mais, estima-se que esta contribuição científica possa corroborar para que haja questionamentos acerca da realidade dos idosos que trabalham no intuito de thes proporcionar melhores condições de vida nos aspectos abordados (apesar de o grupo amostral ter demonstrado predominante satisfação nas respostas), assim como em outros.

\section{REFERÊNCIAS}

ALVES, Élen dos Santos; OLIVEIRA, Nathalia Alves de; TERASSI, Mariélli; LUCHESI, Bruna Moretti; PAVARINI, Sofia Cristina lost; INOUYE, Keika. Dor e dificuldade para dormir em idosos. BrJP, São Paulo, v.2, n.3, p.217-224, 2019. Disponível em http://www.scielo.br/scielo. Acessado em 15 de janeiro. 2021. ISSN 2595-3192. https://doi.org/10.5935/2595-0118.20190039.

ABREU, A. C.; MATA, J. G. A relação do idoso com a família. In: Universidade São Judas Tadeu. Trabalho de Conclusão de Curso. Núcleo de Psicologia. p.29. São Paulo, 2001.

ARAÚJO, C. D. S. F. Aspectos religiosos do idoso. In: PETROIANO, A.; PIMENTA L. G. Clínica e cirurgia geriátrica. Rio de Janeiro, Guanabara, p.8-9, 1999.

BAPTISTA, A. L. Espiritualidade na prática clínica. In: Arte Terapia Coleção Imagens da Transformação. Revista POMAR. Rio de Janeiro, n.08, v.10, p. 18-23, 2003. 
BEE, Helen. O ciclo vital. Porto Alegre: Artes Médicas, 1997.

BERES, V. L. G. A gente que tem o amarelão tem que se conformar: Atenção à saúde na perspectiva do idoso. In: Pontifícia Universidade Católica de São Paulo. Dissertação de mestrado, Curso de Psicologia, Núcleo de Psicologia Social - p.76. São Paulo, 1994.

BREVIGLIERI, N. M. A qualidade de vida do idoso a partir da aposentadoria. In: Universidade São Judas Tadeu. Trabalho de Conclusão de Curso - Curso de Psicologia, Núcleo de Psicologia Psicodinâmica - p.83. São Paulo, 2002.

COLALTO, R. M. C. Qualidade de vida na terceira idade. In: Universidade Camilo Castelo Branco. Monografia como pré-requisito de Trabalho de Conclusão de Curso de graduação em Psicologia - p.49. São Paulo, 2002.

COUTRIM, Rosa Maria da Exaltação. Idosos Trabalhadores: perdas e ganhos nas relações intergeracionais. In: Artigo baseado na tese de doutorado Faculdade de Filosofia e Ciências Humanas da Universidade Federal de Minas Gerais, 2005. Artigo apresentado no XII Congresso Brasileiro de Sociologia realizado em 2005. Sociedade e estado, Brasília, v.21, 2, p.367-390, maio/ago, 2005.

DINIZ, L. Espiritualidade e Arte Terapia. In: Arte Terapia Coleção Imagens da Transformação. Revista POMAR. Rio de Janeiro, n.10, v.10, p.109-124, 2003.

GEIB, Lorena Teresinha Consalter; CATALDO NETO, Alfredo; WAINBERG, Ricardo; NUNES, Magda Lahorgue. Sono e envelhecimento. Revista de Psiquiatria do Rio Grande do Sul, Porto Alegre, v.25, n.3, p.453-465, 2003. Disponível em http://www.scielo.br/scielo. Acessado em 15 de janeiro. 2021. ISSN 0101-8108. http://dx.doi.org/10.1590/S0101-81082003000300007.

MARTINS, Josiane de Jesus; ALBUQUERQUE, Gelson Luiz de; NASCIMENTO, Eliane Regina Pereira do; BARRA, Daniela Couto Carvalho; SOUZA, Wanusa 
Graciela Amante de; PACHECO, Wladja Nara Sousa. Necessidades de educação em saúde dos cuidadores de pessoas idosas no domicílio. Texto \& contexto enfermagem, Florianópolis, v.16, n.2, p.254-262, Junho/2007. Disponível em http://www.scielo.br/scielo. Acessado em 3 de dezembro. 2020. https://doi.org/10.1590/S0104-07072007000200007.

NERI, Anita Liberalesso. Desenvolvimento e envelhecimento. Campinas, Papirus (1ed.), 2001.

ORLANDO, Cássia; DIAS, João Carlos; BRASIL, Ricardo Taveiros; ARAÚJO, Tiago Coelho; BURITI, Marcelo de Almeida. Religiosidade na dimensão biopsicossocial do sujeito idoso. In: Universidade São Judas Tadeu - USJT. Artigo apresentado no XIV Simpósio Multidisciplinar da USJT realizado em 2008. São Paulo.

PANZINI, Raquel Gehrke; ROCHA, Neusa Sica da; BANDEIRA, Denise Ruschel; FLECK, Marcelo Pio de Almeida. Qualidade de Vida e Espiritualidade. Revista de Psiquiatria clínica. São Paulo. v.34, n.1, p.105-115, 2007. Disponível em http://www.scielo.br/scielo. Acessado em 28 de janeiro. 2021. https://doi.org/10.1590/S0101-60832007000700014.

TRENTINI, Clarissa Marceli; XAVIER, Flavio M. F.; FLECK, Marcelo Pio de Almeida. Qualidade de vida em idosos. In: PARENTE, M. A. M. P. Cognição e envelhecimento. Porto Alegre, Artmed (1ed), p.19-20, 2006.

ZIMERMAN, Guite I. Velhice: Aspectos Biopsicossociais. Porto Alegre, Artmed, 2000.

Enviado: Agosto, 2021.

Aprovado: Novembro, 2021.

RC: 101603

Link de acesso: https://www.nucleodoconhecimento.com.br/psicologia/idosos-quetrabalham 